\title{
EXAMINING TRUST IN MOBILE BANKING TRANSACTIONS: THE CASE OF M-PESA IN KENYA
}

\author{
Olga Morawczynski \\ University of Edinburgh, Scotland \\ Gianluca Miscione \\ University of Oslo, Norway
}

\begin{abstract}
This chapter examines how trust can emerge and be sustained in the context of mobile transactions. It focuses on M-PESA, a mobile banking system in Kenya, using data from an ethnographic study that was deployed in Kibera-one of Africa's largest slums. We present research in progress and discuss two main findings. Firstly, interpersonal trust relations between the customers and agents are weak. Customers do not trust the agents with their money. Secondly, the institutional trust relations between the customer and Safaricom, the mobile service provider offering M-PESA, are strong. This means that customers use the M-PESA service because they believe that their money will be kept safe by Safaricom. After providing empirical evidence to substantiate these claims, this study concludes by suggesting questions for future research.
\end{abstract}

Keywords: Mobile banking, M-PESA, trust, Kibera.

\section{Introduction}

This chapter examines how trust can emerge and be sustained in the context of mobile transactions, through an ethnographic study of M-PESA, a mobile banking system deployed in Kibera-one of Africa's largest slums.

The topic of trust was chosen for analysis because we are dealing with economic transactions and the exchange of e-money via the M-PESA application. Such exchange, as pointed out by several authors, is contingent upon trust [13, 15]. We can thus make the argument that the trajectory of M-PESA is dependent upon the trust relations that are established between the actors involved in these exchanges. Using this argument as a starting point, we will examine the nature of these relations and identify the actors involved in establishing and maintaining them in the context of Kibera.

This work intends to be situated between what Avgerou [4] termed social embeddedness and transformative discourses in IS in development contexts. The 
former type of discourse views ICT innovation as "a locally socially constructed course of action" [4 pp.7] and focuses on locally embedded meanings of a technology. The latter also pays attention to the social context and local embeddedness of a technology. However, "while socially embedded analyses tend to take social, economical and political relations in a developing country community or the world as large as a given, the transformative is explicitly concerned with the way ICT are implicated in the dynamic of their change" [4, p. 8]. Through ethnographic research, we aim at understanding how local meanings are ascribed to the technology. We also want to examine how the M-PESA application is implicated in the dynamics of social, economic, and political arrangements. Such understandings must take into consideration trust relations. These relations, as mentioned above, affect the trajectory of innovation.

\section{Introducing mobile banking}

The pervasiveness of the mobile phone in developing countries has recently instigated the development of applications designed to alleviate poverty. One of the most recent is m-banking-a platform for the delivery of financial services via the mobile phone. According to the international development community, the aim of these initiatives is to empower poor constituents by providing them access to formal financial services. The main concern within the m-banking literature is related to adoption. Many studies pose the question of whether or not these applications have the potential to be transformational ${ }^{1}$, or appropriated by a large segment of the unbanked population $[11,18]$. To date, there is very little empirical work examining the adoption of m-banking applications and discussing the numerous barriers to this process.

\section{Presentation of the case}

M-PESA is an m-banking application that facilitates branchless banking via the mobile phone. It targets the unbanked, prepaid segment of the population and was officially introduced onto the Kenyan market in March of 2007 by Safaricom, the Kenyan mobile service provider. It was funded by Department for International Development (DFID), the part of the UK government that provides aid to developing countries in conjunction with Vodafone, the UK telecommunications company [20].

This m-banking application facilitates numerous financial services such as checking account balances, making deposits and withdrawals, transferring money and phone credit to other users. To access these services, individuals must register at one of the retail agent outlets, and deposit cash. This cash is thereafter reflected

\footnotetext{
${ }^{1}$ Please note that the definition of "transformational" in the literature cited is still vague. It is not made explicit when a technology becomes transformational or what constitutes "a large segment of the unbanked population". We have used this definition in the context of this research to emphasize the interest placed in adoption and usage by the international development community.
} 
as e-money in a virtual account that is managed by Safaricom. This is called the non-bank led model of $\mathrm{m}$-banking because the customer has no direct relationship with a bank. After this account is created, and an e-money balance established, all of the aforementioned transactions can be conducted via the mobile phone. To access e-money transferred via M-PESA, the recipient must also visit a retail agent. They provide the agent with identification, verify the transaction number, and convert the e-money balance on their phone into cash.

The transferring money option is particularly interesting in this context because it facilitates the transfer of remittances-both domestic and international. In regards to the latter, Safaricom is currently testing the transfer of e-money between Kenya and the UK. If successful, there are plans to extend this service to other countries that are major sources of remittances because they have a large segment of Kenyan emigrants. This includes the US, France, and Germany [3].

Safaricom reports that within one year of its launch it had close to two million M-PESA customers register with the service and over 2000 active M-PESA agents [24]. Over 9 billion $\mathrm{Ksh}^{2}$ had been transferred through the system during the first year [1]. Reports emerging from the international development community are quite optimistic that such growth rates will continue and argue that these applications have the potential to be "transformational" [18, 19]. They further assert that such appropriation will instigate economic development as poor constituents will be provided the opportunity to participate in the formal economy-some for the first time. However, before M-PESA has this so-called "transformational" effect, it must first be adopted and appropriated by a large segment of the unbanked population. As will be discussed in more detail later, the establishment and maintenance of trust is vitally important in this process.

\section{The empirical setting}

Kibera is one of the most impoverished areas in Kenya. The slum is located $7 \mathrm{kms}$ southwest of Nairobi and it is estimated that one million people, or $60 \%$ of the population in Nairobi, call Kibera their home [10]. The unemployment is some of the highest in the country and only $17 \%$ of the adult population is reported to be permanently employed [10]. The rest are casual labourers or employed in the informal sector. The health indicators in the slum are also extremely poor. It is estimated that $20 \%$ of the community is infected with the HIV virus [10]. This is almost four times the national average. Although Kibera is situated on property that is government owned, the social amenities are extremely poor. There are no government clinics or hospitals and the police are reported to visit the slum only to collect bribes. The majority of dwellers do not have electricity. During the evenings the slum becomes engulfed in darkness and, because of the security risks, few residents leave their homes. Water is also a problem, as the supply is not

\footnotetext{
${ }^{2}$ Approximately $£ 73$ million.
} 
reliable. The residents must either depend on private vendors selling the water by cart or the nearby river, into which Kibera's sewage drains.

There are no formal financial institutions in Kibera. The majority of the population cannot afford the monthly fees required by the larger banks. They also do not have a steady income which they can put away in an account. Money transfer services such as Western Union and Postapay are also not available and residents must travel into town to access such services. It must be noted that in Kibera there is a demand for both banking and money transfer services. In regards to the former, many of those interviewed asserted that they did want to put away their limited savings in a safe place. Many of those interviewed who were unbanked would store their money under their mattresses in "home banks". These were small tin boxes with a slit on the top that was used to insert the money. There was also a great demand for money transfer services. Most of the residents in Kibera are migrants from rural areas who have come to the city to work. They thereafter send remittances to relatives and friends in the rural area. This underrepresentation of these institutions can be explained by the lack of security within the slums. As mentioned previously, there is very little police presence. This means that the organisations dealing with money may not receive adequate protection should there be trouble. It also means that close to one million people in Kibera have limited access to formal financial services.

Although there are no financial organisations within the boundaries of Kibera, there were, at the time of the study, five M-PESA agents. It must be noted, however, that after the disputed Presidential elections that took place in late December 2007 riots broke out in Kibera. Only one of these agents was operational during these riots. The rest closed due to security concerns. Two of the shops were vandalized and remained closed as at May 2008. Despite these security issues, it has been reported by Safaricom that the number of agents and the customer base is expected to increase rapidly in Kibera. As will be discussed below, the telecommunications company has been aggressively marketing the $\mathrm{m}$ banking application focusing on capturing the unbanked segment of the population.

\section{Discussing trust}

There exists a wide body of literature on the topic of trust. However, a concise definition of the term remains elusive as it holds a variety of meanings across disciplines. Because we are examining trust in the context of exchange around $\mathrm{m}$ banking, we will appropriate a definition that is inherently relational $[12,14,15$, $16,20]$. The starting point to our definition of trust is that it possibly emerges as a property of relations between two or more social actors. These actors can be individuals. They can also be institutions such as corporations or political parties [22]. These actors are interacting in some way and have expectations regarding each other's future behaviour [5,8]. They expect that the other actor will fulfil their obligations, behave in a predictable manner, and will act fairly in situations 
of opportunism. In this regard, trust is the expectations that people have of each other, and of the institutions with which they deal. According to Barber [5], these expectations are socially learned and socially confirmed. They change over time, as the actors involved in the trust relations interact and gain more information about each other.

There are several levels at which trust can be examined because, as mentioned above, different types of actors are involved in trust relations. Some scholars pay attention to the trust relations that emerge between individuals, which is known as interpersonal trust $[6,7,16]$. This type of trust is established between two or more interacting individuals who through time learn about each other. As they learn, they make judgements regarding each other's disposition, intentions, and motives. Several authors have also pointed to something called extended trust to explain trust relations that extend beyond those that we know personally [21]. They argue that this type of trust is essential for an efficient market economy because it fosters co-operation between individuals who may not have prior information about each other. Several explanations have been given as to why individuals choose to cooperate, even without this information. Some argue that an individual's role in society can form a basis of presumptive trust. It is not the actual person that is trusted but the system of expertise that produces and sustains role-appropriate behaviour [12]. For example, Dawes [9] asserts that "we trust engineers because we trust engineering and believe that engineers are trained to apply valid principles of engineering, moreover, we have evidence everyday that these principles are valid when we observe planes flying" [12, p. 9].

Whilst some pay attention to relations that emerge between individuals, others examine those that exist between individuals and institutions such as corporations or political parties. This is commonly referred to as institutional trust [17, 25]. It is different from interpersonal trust because it is based on trust in institutional arrangements rather than in people. Institutional trust, however, also includes an element of interpersonal trust [22]. This is because the beliefs held about a particular institution can be contingent upon the personnel which they staff. For example, Zimmer [26] argued that institutional leaders can greatly affect the way in which the entire institution is perceived. To make this point, Zimmer examined the impacts of the Watergate scandal on perceptions of trust by the public of the government. He concluded that the violated trust of Nixon led to a generalized distrust for the American government.

In this research, we will use the aforementioned discussion on trust to delineate how it emerges and is sustained in mobile transactions in Kibera. Using M-PESA as an example, we will examine inter-personal trust relations between the customer and agent. We will further explore the institutional trust relations between the customer and Safaricom-the mobile service provider offering the MPESA service. 


\section{Questions for discussion and data gathering techniques}

At this early stage of research, the focus will be on answering the following:

- What type of trust is needed in the context of mobile transactions?

- How does it emerge?

- How is it negotiated?

- Who is involved in these negotiations (directly and indirectly)?

To help answer the aforementioned questions and instigate discussion on the concept of trust in mobile transactions, we will use data gathered in an ethnographic study in Kibera from September 2007-December 2007. During this period, we used participant observation and semi-structured interviews in Eva's Impressions, a mobile phone shop that provides M-PESA services. The shop is situated along Kibera Drive, which is the main passageway to town. It has been opened since 2006 and sells a variety of Safaricom products including scratch cards, SIM cards and mobile phones. The shop started offering M-PESA services in June of 2007. Based on our visits to other M-PESA agents in Kibera, we found Eva's to be the busiest. We visited the shop from one to two times per week and spent time speaking to three classes of individuals - the users, the non-users, and the agents. ${ }^{3}$

We hired two research assistants to help with the interviews. They both spoke Swahili and were familiar with Kibera. One of the assistants lived in the slum and thus knew many of the people that came into the shop. This facilitated the interview process.

\section{The preliminary findings}

\subsection{Findings related to usage}

Before we discuss the findings in regards to trust and mobile transaction, let us first examine how the application was used. There are two ways in which we monitored usage. Firstly, we counted the number of transactions that were recorded in the agent's logbook, and noted the transaction type. In Eva's we found that there were between 50-65 transactions per day. There are usually more deposits than withdrawals, but at times the amount of deposits and withdrawals were equal. However, according to the agents, customers would often make large deposits and several small withdrawals. This led us to suspect that the service was being used not just to send, but also to store money. We further learned that the frequency of transactions increased at particular points of the year. September was reported to be the busiest month because it is the beginning of the school term.

\footnotetext{
${ }^{3}$ It must be noted that these particular groups are not stable. For example users may become non-users should they find that the application is too difficult to use, or does not adequately fit in with their financial habits. It is also important to recognize that actors may fit into more than one of these groups. For example, the users may also be agents.
} 
During this period, many Kenyans send their relatives in rural areas money for school fees. The last week of each month was also reported to be busy. This is when Kenyans receive their paychecks.

We also monitored usage by speaking with the customers in the shop. Our preliminary findings show that most individuals were using M-PESA to send money to their relatives, or to top-up their mobile phone credit. We also found that some were using the application to exchange money with business partners. For example, a female resident of Kibera, who had her own spinning business, used M-PESA to send money to her suppliers in Mombasa and collect debts from her customers. She claimed that M-PESA "makes business easier" because it saves her both time and money. There were also occasions when M-PESA was being used to "help a friend in need". An interview with a young woman revealed that she was using M-PESA to send money to a friend who was "stranded" and needed "fare for the bus" because she had been robbed. The woman sending the money said that she'd never had a bank account, and did not know of any other way that the money could be sent.

Some customers also claimed that they were using M-PESA to store their money. We were surprised to find, however, that the majority of these individuals had one or more bank accounts in town. They claimed that they were using MPESA because they could access their money without having to travel outside of Kibera. According to our interviewees, such travel was both costly and time consuming. We also found that many of the customers who were using M-PESA to send money were unaware that it could be used for other purposes. In fact, several individuals that we interviewed asked us whether the application had "other uses". This lack of information on the various functionalities of M-PESA can be attributed to the way in which the application is being marketed. M-PESA is being presented mainly as an application that facilitates money transfers from urban to rural areas. Radio adverts and billboards advertising M-PESA throughout Nairobi also fail to mention the other uses. The slogan used for such advertisements is "Tuma pesa kwa simu", meaning "Send money by mobile phone" in Swahili.

\subsection{Findings related to trust}

We also have several results that can be used in our discussion of trust. One of our first findings is that many of the M-PESA customers do not trust the agents with their money.

The agents often complained that they would receive the blame for all the problems with the M-PESA system. Because M-PESA utilizes the same data channel as text messages, it often becomes congested at "peak texting times". The result is that many M-PESA transactions fail. They are either not processed in the system, or are processed but the SMS that confirms the M-PESA transaction to the agent and customer is not sent. The agents asserted that in both of these cases, they were accused of stealing the customer's money after a deposit was made and 
no confirmation SMS received. A conversation with an M-PESA agent in Eva's revealed the following:

I asked the agent whether she, or her customers, had lost money when the system became congested. She said no. She then added that on several occasions her customers "thought that they had lost money". Last week, she explained, she had a customer come in to make a deposit. He wanted to send the money to his relatives. This customer gave her the money and he was told to wait for the confirmation SMS. However, after waiting around for nearly an hour, he told the agent that he had to leave for work and would be back if he did not receive the confirmation. He came back the next day to "hassle" her, she explained. She tried to make it clear to him that the money was "in the system", but the customer demanded his "stolen" money back. He then became "angry" and began to "quarrel". She had to call the Safaricom people to reverse the transaction so that she could give the man his deposit.

Most of the agents interviewed had similar stories and told us that they were often accused of stealing money from the customers.

Our data further revealed that some customers did not expect others to trust the agents. In fact, the agents told us that some customers would come into the shop with their debtors and attempt to withdraw money. This was even when the customers did not have enough money in their accounts to make the requested withdrawal. We saw one incidence of this with a man who had a debt with a peanut seller:

We heard some yelling outside of the shop before we saw a man stumble in with a cigarette in one hand and a pack of peanuts in the other. He smelled of alcohol and his white shirt had large brown stains, and what appeared to be cigarette burns. He was followed by another man who was holding a large basket of peanuts. They were exchanging words in Swahili, and the man in the white shirt was yelling in English "get the money from the agent" as he entered the shop while pointing at Cheryl [the agent]. Before the peanut seller could make his way into the shop, the man in the white shirt pushed passed him and they ran out into the street. They continued to yell at each other, and a crowd was beginning to gather.

Once they left, we all started to laugh. Christine [my research assistant] turned to me and explained that the man told the peanut seller to collect the " 5 bob" for peanuts from Cheryl. The peanut seller demanded his money in cash, and refused to believe that the man in the white shirt had " 5 bob" in an M-PESA account. Cheryl explained that this sort of thing happens very often. Customers who are in debt will come in with their debtors and try to withdraw money from their MPESA account. The agent will check the account and realize that the customer does not have enough money for the requested withdrawal and inform the customer. The customer will then become angry and inform the debtor that the

\footnotetext{
4 "Bob" is the slang name used for Kenyan shilling.
} 
agent is lying and that the agent does not want to give the customer their money. Cheryl emphasized that "it is always our fault".

Our interviews with the customers confirmed that many do not trust the MPESA agents. One on occasion, an angry customer complained to us that the agent at Eva's had stolen money from him. He asserted that he had made a deposit of "400 bob" the week before and when he checked his balance that morning he only had "399 bob". He demanded that the agent return the "1 bob" that was stolen. The M-PESA agent had to spend several minutes explaining that there was "1 bob" deducted from his account every time that he checked his balance. The man was not convinced and asked for some evidence. The agent showed him a leaflet with the different transaction costs. The customer then stamped out the door with leaflet in hand.

From these findings we can make the argument that interpersonal trust relations between the customers and agents are still weak. This could be because the application has only recently been introduced into Kibera. Many of the customers interviewed had signed up within the last few months and used the application monthly or bi-monthly. This means that they have had limited interaction with the agents. It can thus be argued that at this stage M-PESA customers are gaining information and making judgments regarding the disposition, intentions, and motives of the agents. Such information will help them to form expectations regarding the future behaviour of the agents. As we have seen from the field notes above, one such expectation is how money deposited will be handled by the agent. Customers want to make sure that their money is fully reflected in their M-PESA account and that it can be accessed when needed. We can further make the argument that trust relations are weak because all of the agents in the shop live outside of Kibera. They are thus not known personally by the customers. In this case, what we earlier called extended trust relations need to be established between the customer and the agent.

If many customers do not trust the agents with their money, then we must ask ourselves why they use M-PESA. The data gathered suggests that they use the service because they trust Safaricom. This means that the trust relations between the customers and Safaricom are much stronger than those between the customers and agents. This could be because the company has a history in Kenya. It has provided mobile services since 1997. As at May 2008, the company was reported to have $70 \%$ of the Kenyan market, which amounts to 9.5 million subscribers (in a country of 36 million) [2]. As such, many of the M-PESA customers have been using Safaricom as their mobile service provider before the M-PESA service was introduced. They have thus had more exposure to the mobile service operator and more time to assess the quality of the institutional arrangements. These assessments, as mentioned above, are vital for the emergence of institutional trust. In the context of m-banking transactions, such trust is important because customers are handing over their money to be held in a virtual account managed by Safaricom. As such, they must have faith that the institution will protect such deposits and make them available to the customer when needed. 
It was also previously discussed that institutional leaders may affect the way in which the institution is assessed, and whether it is trusted. From the fieldwork data, we found this to be correct. An interview with an M-PESA customer revealed the following:

Andrew made clear that there were several problems with Equity [the name of his bank]. I leaned forward and asked him what they were. "I don't mean to be tribal" he replied, "but the president of Equity is too close to Kibaki [the CEO of Kenya]". I asked him to explain and he told me that the president of Equity Bank, who was Kikuyu like Kibaki, was giving "too much" of the "common man's" money to support Kibaki's electoral campaign. If this went on, he emphasized, the bank would crash and the money of the "common man" would be lost. He then said that this is why spreading out your money in several accounts was a "good idea"...I asked him whether he was afraid that Safaricom would crash and that he would lose the money in his M-PESA account. He shook his head. He said that everyone knew that Safaricom would not involve themselves in "tribal politics" because Micheal Joseph (the president of Safaricom) did not belong to any of Kenya's tribes.

In the case of Andrew, he trusted Safaricom with his money because Micheal Joseph, its President, did not have tribal affiliations. Our interviews with other customers also revealed that Joseph was well respected in the community. Because of his South African background, he seemed to be excluded from accusations of tribal favouritism. We can thus make the argument that many of those interviewed trust Safaricom because they trust Joseph. We can further argue that they trust Joseph because they believe that he is politically neutral. Such a finding confirms the aforementioned research suggesting that the organisational leader affects the way in which an institution is perceived. In this case, Joseph's good standing in the community has positively impacted public opinion of Safaricom.

\section{Conclusions}

From these few early examples, we can see that trust is a vital element of social relations, and is shaping the trajectory of the M-PESA application. Our preliminary findings suggest that many of the customers trust the M-PESA system because it is affiliated with Safaricom. This means that institutional trust relations between the customers and the mobile service provider are strong. Our findings further suggest that interpersonal trust relations are weak as customers do not trust the agents within the M-PESA network. We have shown that on numerous occasions the agents were accused of stealing the customer's money when there was a problem with the application. As the study progresses, other examples will be gathered and used to discuss the issue of trust.

Finally, based on the results collected thus far, further research will focus on the following questions: 
- Do people establish trustworthy relations beyond their immediate circles? If so, why do they extend their trust beyond these boundaries?

- What about brand trust? How did Safaricom gain trust? How does it sustain it?

- What about distrust and power? How can these concepts be incorporated into the analysis?

\section{References}

[1] (2008, March 28). Kenya: Clear M-Pesa's legal hurdles. Business Daily. Nairobi.

[2] (2008, March 14). Kenya sets \$3bn Safaricom IPO price. Reuters. Retrieved April 20, 2008, from http://www.engineeringnews.co.za/article.php?a_id=129263.

[3] Aron, M. (2007). Kenya: trend-setting M-Pesa goes international. Business Daily. Nairobi.

[4] Avgerou C. (2007) Information systems in developing countries: a critical research review, London School of Economics and Political Sciences, Innovation Group, Working Papers Series, October 2007.

[5] Barber, B. (1983). The logic and limits of trust. New Brunswick: Rutgers University Press.

[6] Boon S.D. \& Holmes J.G. (1991). The dynamics of interpersonal trust: Resolving uncertainty in the face of risk. In Cooperation and Prosocial Behavior, ed. RA Hinde, J Groebel (pp. 167-82). New York: Cambridge University Press.

[7] Brann, P. \& Foddy, M. (1988). Trust and the consumption of a deteriorating resource. Journal of Conflict Resolution, 31, 615-30.

[8] Dasgupta, P. (1988). Trust as a commodity in D. Gambetta (ed.) Trust: Making and breaking cooperative relations, (pp. 49-72). New York: Basil Blackwell.

[9] Dawes, R.M. (1994). House of cards: Psychology and psychotherapy built on myth. New York: Free Press.

[10] Ilako, F. \& Kimura, M. (2004 ). Provision of ARVs in a resource-poor setting: Kibera Slum. International Conference on AIDS. Nairobi, Kenya, African Medical and Research Foundation (AMREF).

[11] Ivatury, G. \& Pickens, M. (2006). Mobile phone banking and low-income customers: Evidence from South Africa, Consultative Group to Assist the Poor/The World Bank.

[12] Kramer, R. (1999). Trust and distrust in organizations: Emerging perspectives, enduring questions. Annual Review of Psychology, 50, 569-598.

[13] Luhmann, N. (1979). Trust and power. New York: Wiley.

[14] Mayer, R., Davis, J., \& Schoorman, FD. (1995).An integrative model of organizational trust. The Academy of Management Review, 20,709-34.

[15] Malinowski, B. (1922). Argonauts of the Western Pacific: Account of native enterprise and adventure. London, Routledge and Kegan Paul Ltd.

[16] McAlister, D.J. (1995). Affect- and cognition based trust as foundations for interpersonal cooperation in organizations. The Academy of Management Review, 38, 24-59.

[17] Mishler, W. \& Rose, R. (2001) What are the origins of political trust? Testing institutional and cultural theories in post-communist societies, Comparative Political Studies, 34 (1), 30-62.

[18] Porteous, D. (2006). The enabling environment for mobile banking in Africa. Boston, DFID.

[19] Porteous, D. (2007). Just how transformational is m-banking?, Finmark Trust.

[20] Putnam, R. (1993). Social capital and public life. The American prospect, 13. 


\section{Social Dimensions of ICT Policy}

[21] Raiser, M., Haerpfer, C., Nowotny, T., \& Wallace, C. (2001). Social capital in transition: a first look at the evidence. Working Paper No 61. European Bank.

[22] Smith, M.L. (2007). Confianza a la Chilena: A comparative study of how e-services influence public sector institutional trustworthiness and trust. PhD Thesis. London School of Economics and Political Science.

[23] Vaughan, P. (2007). Early lessons from the deployment of M-Pesa, Vodafone's own mobile transactions services. The transformational potential of m-transactions, Vodafone Group PLC: 6-10.

[24] P. Vaughan, personal interview, March 27, 2008.

[25] Williamson, O.E. (1985). The economic institutions of capitalism. New York: Free Press.

[26] Zimmer, T. (1972). The impact of Watergate on the public's trust in people and confidence in the mass media. Social Science Quarterly. 59,743-751. 